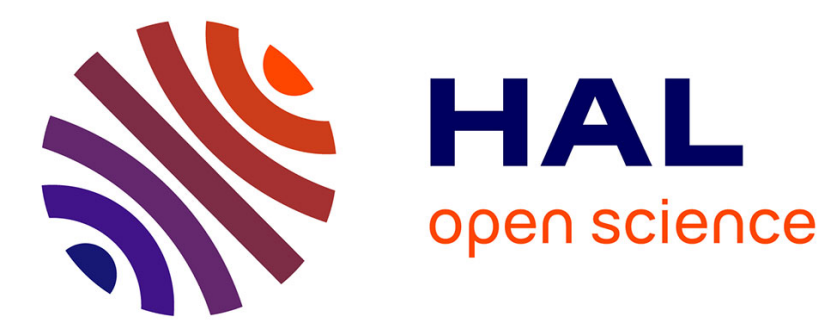

\title{
Influence of fused filament fabrication parameters on tensile properties of polyactide/layered silicate nanocomposite using response surface methodology
}

Geoffrey Ginoux, Isabelle Vroman, Sébastien Alix

\section{- To cite this version:}

Geoffrey Ginoux, Isabelle Vroman, Sébastien Alix. Influence of fused filament fabrication parameters on tensile properties of polyactide/layered silicate nanocomposite using response surface methodology. Journal of Applied Polymer Science, 2021. hal-03467209

\section{HAL Id: hal-03467209 \\ https://hal.science/hal-03467209}

Submitted on 6 Dec 2021

HAL is a multi-disciplinary open access archive for the deposit and dissemination of scientific research documents, whether they are published or not. The documents may come from teaching and research institutions in France or abroad, or from public or private research centers.
L'archive ouverte pluridisciplinaire HAL, est destinée au dépôt et à la diffusion de documents scientifiques de niveau recherche, publiés ou non, émanant des établissements d'enseignement et de recherche français ou étrangers, des laboratoires publics ou privés. 


\title{
INFLUENCE OF FUSED FILAMENT FABRICATION PARAMETERS ON TENSILE PROPERTIES OF POLYLACTIDE/LAYERED SILICATE NANOCOMPOSITE USING RESPONSE SURFACE METHODOLOGY
}

\author{
GEOFFREY GINOUX*, ISABELLE VROMAN, SÉBASTIEN ALIX \\ Institut de Thermique, Mécanique, Matériaux - Université de Reims Champagne-Ardenne, \\ 51100 Reims (France) - Email: geoffrey.ginoux@univ-reims.fr
}

\begin{abstract}
.
This study aimed at assessing and optimising the influence of printing speed and extrusion temperature in a fused filament fabrication (FFF) process on the tensile properties of a polylactide/layered silicate nanocomposite. Mathematical models using Doehlert designs were formulated to examine factor and interaction effects. The models were corroborated by measurements using capillary rheology, tomographic images, and crystallinity analyses to find physical explanations for the differences in tensile properties. The tensile properties were a non-monotonic function of printing speed, which may be due to various deposition defects that influence the porosity of composite tensile specimens. This study provides new insights into FFF process optimisation regarding rheological behaviour and mesostructure of nanocomposite by highlighting new modes of deposition defects that originate from process parameter settings and materials. The results contribute to the properties mastery of FFF-processed materials.
\end{abstract}

\section{Introduction}

Additive manufacturing (AM) techniques are currently the subject of considerable interest due to their promising applications. Initially used for rapid prototyping, AM makes it possible to manufacture complex parts because its layerby-layer approach enables the manufacture of expensive end-use products at a lower cost or of parts impossible to manufacture using traditional subtractive or formative techniques. While AM refers to several technologies ${ }^{1,2}$, fused filament fabrication (FFF) is one of the most commonly used due to its speed and cost-effectiveness ${ }^{3}$. However, additively manufactured parts have inferior mechanical performance compared to those produced by subtractive and formative processes because of manufacturing defects ${ }^{4}$, which hindered the development of this technology for smallscale production or medical applications ${ }^{5}$. Manufacturing defects in those parts include porosity ${ }^{6}$ and distortion ${ }^{7}$, which can initiate fracture during mechanical tests. Those defects are due to the spreading of the molten material in successive layers which causes an anisotropic structuring, provoked by the raster angle during the process ${ }^{8}$. Currently, an important topic in this field is predicting the mechanical properties as a function of printing parameters to limit those defects and to obtain desirable properties. Numerous parameters can be adjusted to modify the mechanical properties of the product, including shell number, layer thickness, infill percentage, deposition angle, build orientation, raster width, displacement speed of printing head, and temperature of liquefier ${ }^{9}$. Those parameters modify the structure of the built parts, namely porosity and crystallinity ${ }^{10}$, and thus the mechanical properties ${ }^{11}$. Printing parameters may influence the thermal cycles 
and cause a differential of shrinkage, which could cause distortion, internal residual stress and lower mechanical properties $^{12}$. Printing speed and extrusion temperature have been shown to impact the adhesion between deposited filaments ${ }^{13}$, and are suspected to indirectly modify the structure by influencing the ability of the filament to be correctly deposited $^{14,15}$. To date, the impact of printing speed on mechanical properties is not clear, and has been shown to have both positive and negative effects ${ }^{14-19}$. In general, it seems that a low printing speed leads to better adhesion between layers. This effect was reported by Deng et $a l .{ }^{14}$. They reported that low speeds lead to uneven deposition. Other studies showed a better adhesion at low speeds ${ }^{18,19}$. Sukindar and Jaafar ${ }^{15}$ stated that high speeds reduce the consistency of the extrusion process, which would lead to turbulent flow and irregular deposition. Regarding extrusion temperature, Spoerk et al. ${ }^{20}$ reported a positive effect, since an increase in temperature decreases viscosity and promotes filament adhesion. The poor filament adhesion would increase the anisotropy of the printed part by lowering the mechanical properties in the building direction ${ }^{21}$. Other phenomena might also influence the effect of temperature on mechanical properties, such as crystallinity ${ }^{10,22}$ or matrix degradation ${ }^{23}$, and cause a more difficult understanding of this thermal behaviour. Printing speed and temperature are thought to interact, since printing speed can modify the time between two adjacent depositions, which is the time allowed for a filament to weld before the temperature falls below the glass transition ${ }^{24}$. The dependence of mechanical properties on thermo-kinetic parameters is suspected to be more nuanced than expected, and there may be an optimum combination of properties.

Design of experiments (DOE) is a technique that is often used to model the effects of FFF process parameters and their interactions both cost- and time-efficiently. The response surface methodology (RSM) is particularly effective for observing an optimum response. The most well-known DOEs in the field of additive manufacturing are central composite design, the Taguchi method, and the Box-Behnken method ${ }^{25}$. Doehlert design ${ }^{26}$ is also interesting due to its uniform space-filling and iterative nature, which makes this design effective to find optima, especially in case of complex effects weakly predictable with a single quadratic model. This iterative fashion allows to start with a restricted domain and to widen it only when necessary, improving the time and cost efficiencies of the experiments when the localisation of optima is multiple, i.e. visible in several domains, or not obvious. Surprisingly, while this method is not commonly used in AM studies, it is well known in other fields like chromatography ${ }^{27}$. Existing models are essentially focused on the mechanical optimisation of neat polymers, while nano-filled polymers can also be used to compensate for the previously cited loss of mechanical performance ${ }^{2,28}$, and to help functionalise the materials ${ }^{29}$ or ease the processability ${ }^{30}$. However, filled polymers are known to be stiffer than neat polymer, especially while additively manufactured, and need to compensate the lack of ductility with an optimisation of the process ${ }^{31}$. A Doehlert design was then chosen to understand how printing speed and extrusion temperature influence the mechanical properties of printed polylactide (PLA) filled 
with layered silicates. Rheology is dependent on those factors, which could modify the structure and thus the tensile properties. Hence, capillary rheology, X-ray micro-computed tomography (microCT) and differential scanning calorimetry (DSC) analyses were used to propose physical explanations for the mathematical models obtained with DOE.

\section{Materials and methods}

2.1. Materials and nanocomposite preparation

PLA was purchased from NaturePlast (France) in pellet form as extrusion-grade PLE 005. Table 1 summarises some its properties.

Table 1. Properties of PLE 005 provided by the supplier.

\begin{tabular}{ll}
\hline Properties & Value \\
\hline Specific gravity & 1.26 \\
MFI $\left(190{ }^{\circ} \mathbf{C} ; \mathbf{2 . 1 6} \mathbf{~ k g}\right)$ & $5-9 \mathrm{~g} / 10 \mathrm{~min}$ \\
Glass transition temperature & $60{ }^{\circ} \mathrm{C}$ \\
Melting temperature & $170{ }^{\circ} \mathrm{C}-180{ }^{\circ} \mathrm{C}$
\end{tabular}

The layered silicate was an organically modified montmorillonite (MMT) supplied by Southern Clay Products (Gonzales, TX) under the trade name Cloisite 30B (C30B). The modifier was methyl, tallow, bis-2-hydroxyethyl, and quaternary ammonium with a concentration of $90 \mathrm{mEq}$ per $100 \mathrm{~g}$. The specific gravity of C30B is 1.98 , and that of native MMT is 2.86 .

PLA was first dried at $70{ }^{\circ} \mathrm{C}$ overnight before nanocomposite compounding with a co-rotating twin-screw extruder (BC21, Clextral, France; $\mathrm{L}=900 \mathrm{~mm}, \mathrm{~L} / \mathrm{D}=36$ ) with temperatures set between $165^{\circ} \mathrm{C}$ and $180{ }^{\circ} \mathrm{C}$ at $300 \mathrm{rpm}$. The residence time was approximately three minutes with a mass flow of $1.8 \mathrm{~kg} \cdot \mathrm{h}^{-1}$. A masterbatch of clay at $13.2 \mathrm{wt} \%$ in PLA was obtained. The masterbatch was then diluted with neat PLA in the same extrusion process at a desired loading of around $3 \mathrm{wt} \%$, which is an optimal loading for thermal and mechanical properties ${ }^{32,33}$. Nanocomposite was then pelletised, and the MMT mass fraction was controlled by thermogravimetric analysis for residue after degradation at 800 ${ }^{\circ} \mathrm{C}$ for 10 min under air flow. MMT mass fraction was determined to be $2.7 \pm 0.2 \mathrm{wt} \%$.

\subsection{Filament fabrication}

Nanocomposite pellets were first dried overnight at $70{ }^{\circ} \mathrm{C}$ in a ventilated oven and then shaped into a $1.65 \pm 0.05 \mathrm{~mm}$ diameter filament using a single-screw extruder (BX10, Axon Plastics Machinery ab, Nyvang, Sweden; L/D = 18) with a screw speed at $20 \%$ of maximum and a $460 \mathrm{~g} / \mathrm{h}$ mass flow. The profile temperature, separated into three zones, was set to $190{ }^{\circ} \mathrm{C}, 185^{\circ} \mathrm{C}$, and $185^{\circ} \mathrm{C}$ from the feeding zone to the nozzle. The filament was pulled by a Haake ${ }^{\mathrm{TM}} \mathrm{PP} 1$

(ThermoFisher Scientific, Waltham, MA) to obtain the required diameter.

2.3. Fabrication of specimens 
Once the filament was obtained, tensile test specimens were manufactured using a Replicator 2 (MakerBot Industries, LLC, Brooklyn, NY) with a 0.4 mm-diameter nozzle. The specimens were first modelled using Solidworks ${ }^{\circledR}$ software (Dassault Systèmes, SolidWorks Corporation, Waltham, MA) with dimensions according to 5A-type specimens from ISO 527-2 standard. The STL file was then imported to Makerbot Print software. Specimens were printed with two shells, in a $90^{\circ} / 0^{\circ}$ crossed-deposition fashion (see Figure 1), which gives greater modulus of elasticity than $45^{\circ} /-45^{\circ}$ deposition ${ }^{31,34}$, with a $0.2 \mathrm{~mm}$ layer-height, for a total of ten layers. Printing speed has been modified according to the experimental design but is constant during printing, i.e. it is identical for all the layers of the sample. Build plate temperature was at room temperature. Infill percentage was set to a theoretical $100 \%$.

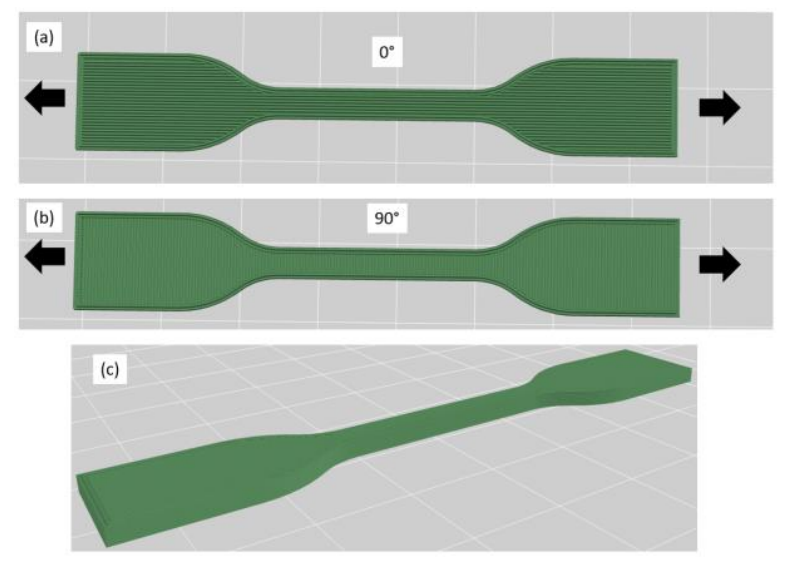

Figure 1. Graphical representations from Makerbot Print Sotfware of a $0^{\circ}$ deposition layer (a), a $90^{\circ}$ deposition layer (b) and a complete sample (c). Green stripes represent the deposition orientations. Black arrows represent tensile direction.

\subsection{Characterisation tests}

Tensile tests were conducted on an Instron (Norwood, MA) 33R 4204 apparatus with a $1 \mathrm{kN}$ load at a constant $5 \mathrm{~mm} / \mathrm{min}$ tensile speed. Data were processed using Bluehill ${ }^{\circledR}$ software (Instron). All measures were repeated five times. Dixon tests (or $Q$-tests) were performed to eliminate anomalous values.

MicroCT characterisation of printed parts was performed on an EasyTom 150 (RX Solutions SAS, Annecy, France) to identify grips and fracture zones. The following parameters were used: $60 \mathrm{kV}, 166 \mu \mathrm{A}$, and 1440 radiographic images at two images per second with a voxel size of around $10 \mu \mathrm{m}$. Data were processed using X-Act software (RX Solutions SAS, Annecy, France).

Capillary rheology data were obtained with a Rosand capillary rheometer (Malvern Panalytical Ltd, Malvern, UK) with two $1 \mathrm{~mm}$ capillary dies of 0.25 and $16 \mathrm{~mm}$ in length. Bagley and Rabinovitsch corrections were used to obtain viscosity as a function of the shear rate at $180,185,190$, and $195^{\circ} \mathrm{C}$. 
Calorimetric measurements were performed on a DSC204 F1 (Netzsch-Gerätebau GmbH, Selb, Germany) calibrated with an indium standard. Tensile test specimens, not used in tensile test, from each configuration of the Doehlert designs were analysed from 25 to $210{ }^{\circ} \mathrm{C}$ at a $10 \mathrm{~K} / \mathrm{min}$ heating rate at three different points in the fracture zone to calculate the standard deviation. Equation (1) was used to calculate the crystallinity rate, $\chi_{c}$.

$$
\chi_{c}=\frac{\Delta H_{m}-\Delta H_{c c}}{\Delta H_{m}^{0}} \times \frac{100}{1-\Phi_{m}}
$$

$\Delta H_{m}$ is the measured melting enthalpy, $\Delta H_{c c}$ is the measured cold crystallisation enthalpy, $\Delta H_{m}^{0}$ is the melting enthalpy of a theoretical $100 \%$ crystalline PLA $\left(91{\mathrm{~J} . \mathrm{g}^{-1}}^{35}\right.$, and $\Phi_{m}$ is the mass fraction of MMT.

\subsection{Doehlert design}

The Doehlert method is an iterative technique for response optimisation. For this study, one iteration was performed. The case with two factors $(k)$ uses a simplex triangle and requires seven experiments $\left(N=k^{2}+k+1\right)$. Since the method is iterative, the values must essentially consider the "size" of the simplex (geometric unit). Differences of $15 \mathrm{~mm} . \mathrm{s}^{-1}$ for printing speed and $25^{\circ} \mathrm{C}$ for extrusion temperature were a good compromise between a sufficiently large gap to observe a difference and a not-too-large gap to avoid missing a local optimum. The iteration included four experiments, from the first design to three new ones (Table 2 and Figure 2).

Table 2. Process parameter values with test numbers for both Doehlert designs and respective configuration numbers for each design, with printing speed as factor 1 and extrusion temperature as factor 2.

\begin{tabular}{|c|c|c|c|c|}
\hline $\begin{array}{l}\text { Test } \\
\mathbf{N}^{\circ}\end{array}$ & $\begin{array}{l}\text { Point } \\
\mathrm{N}^{\circ} \\
\text { First } \\
\text { design }\end{array}$ & $\begin{array}{l}\text { Point } \\
\mathrm{N}^{\circ} \\
\text { Second } \\
\text { design }\end{array}$ & $\begin{array}{l}\text { Printing } \\
\text { speed } \\
\left(\mathbf{m m} \cdot \mathbf{s}^{-1}\right) \\
(1)\end{array}$ & $\begin{array}{l}\text { Extrusion } \\
\text { temperature } \\
\left({ }^{\circ} \mathrm{C}\right) \\
(2)\end{array}$ \\
\hline 1 & 1 & 7 & 75 & 215 \\
\hline 2 & 2 & 3 & 60 & 240 \\
\hline 3 & 3 & & 30 & 240 \\
\hline 4 & 4 & & 15 & 215 \\
\hline 5 & 5 & & 30 & 190 \\
\hline 6 & 6 & 5 & 60 & 190 \\
\hline 7 & 7 & 4 & 45 & 215 \\
\hline 8 & & 6 & 90 & 190 \\
\hline 9 & & 1 & 105 & 215 \\
\hline 10 & & 2 & 90 & 240 \\
\hline
\end{tabular}




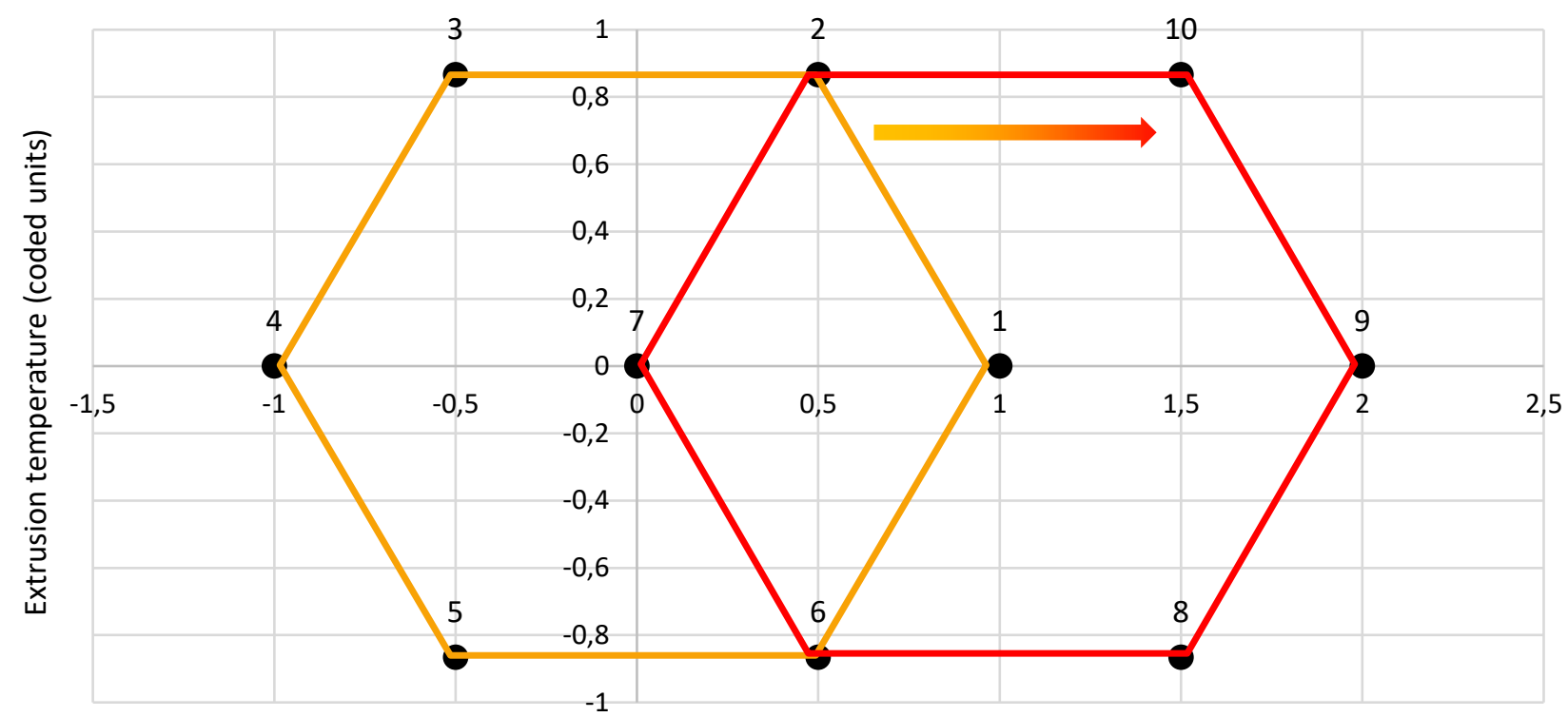

Printing speed (coded units)

Figure 2. Graphical representation of the two Doehlert designs in coded units with printing speed on the $\mathrm{x}$-axis and extrusion temperature on the y-axis (first design on the left, second on the right). Numbered dots represent the 10 experiments placed according to their respective configuration and the arrow shows the direction of the slip between the first and second Doehlert designs.

All calculations were performed with Excel $^{\circledR}$ software (Microsoft Corp., Redmond, WA) using matrix calculations. For each design, the model was written as

$$
y_{t h}=a_{0}+\sum_{i=1}^{k} a_{i} x_{i}+\sum_{i=1}^{k} a_{i i} x_{i}^{2}+\sum_{i=1}^{k-1} \sum_{j=i+1}^{k} a_{i j} x_{i} x_{j}+\varepsilon
$$

$y_{t h}$ is the theoretical response of the experiment at the chosen levels, $a_{0}$ is the response of the central point, $a_{i}$ and $a_{i i}$ are the coefficients of the mathematical model from factor $\mathrm{i}, a_{i j}$ are the coefficients of the interaction between factors $\mathrm{i}$ and $\mathrm{j}$, $x_{i}$ and $x_{j}$ are the factor levels, $k$ is the number of factors, which is 2 in this study, and $\varepsilon$ is the residue.

Analysis of variance (ANOVA) was used to assess the significance of the coefficients and models and normality of the results were checked using Shapiro-Wilk test.

\section{Results and discussion}

3.1. Statistical analysis

Tensile test results for the Doehlert designs are summarised in Table 3. Young's modulus $(E)$ and ultimate tensile strength $\left(\sigma_{M}\right)$ were chosen as responses for the models. Elongation at break and elongation at ultimate tensile strength were not treated by the Doehlert method due to high experimental standard deviations, leading to low significance for all 
the coefficients and models. Data for both designs and both responses follow a normal distribution according to ShapiroWilk test at a 0.05 level.

Table 3. Mean values of Young's modulus and ultimate tensile strength responses as determined by tensile tests for each configuration, with corresponding printing speed and extrusion temperature values, from both Doehlert designs with associated standard deviations.

\begin{tabular}{lllll}
\hline Test & $\begin{array}{l}\text { Printing } \\
\text { speed } \\
\mathbf{N}^{\circ}\end{array}$ & $\begin{array}{l}\text { Extrusion } \\
\text { temperature } \\
\left(\mathbf{m m . s}^{-1}\right)\end{array}$ & $\begin{array}{l}\boldsymbol{E}(\mathbf{M P a}) \\
\left({ }^{\circ} \mathbf{C}\right)\end{array}$ & $\sigma_{M}(\mathbf{M P a})$ \\
\hline $\mathbf{1}$ & 75 & 215 & $1397 \pm 11$ & $59.4 \pm 1.4$ \\
$\mathbf{2}$ & 60 & 240 & $1338 \pm 13$ & $56.3 \pm 0.6$ \\
$\mathbf{3}$ & 30 & 240 & $1295 \pm 41$ & $53.0 \pm 2.0$ \\
$\mathbf{4}$ & 15 & 215 & $1345 \pm 27$ & $56.7 \pm 0.9$ \\
$\mathbf{5}$ & 30 & 190 & $1302 \pm 19$ & $56.9 \pm 1.7$ \\
$\mathbf{6}$ & 60 & 190 & $1354 \pm 19$ & $58.9 \pm 1.5$ \\
$\mathbf{7}$ & 45 & 215 & $1249 \pm 32$ & $59.0 \pm 2.9$ \\
$\mathbf{8}$ & 90 & 190 & $1337 \pm 12$ & $58.4 \pm 0.4$ \\
$\mathbf{9}$ & 105 & 215 & $1362 \pm 18$ & $58.5 \pm 0.9$ \\
$\mathbf{1 0}$ & 90 & 240 & $1357 \pm 11$ & $56.3 \pm 2.1$ \\
\hline
\end{tabular}

Model coefficients after matrix calculations are given in Table 4. Three-dimensional representations of the response surfaces corresponding to each mathematical model are displayed in Figure 3. Details of the ANOVA are summarised in the Appendix (Tables A1 to B2). The models with ultimate tensile strength as a response for both designs are not significant at the $90 \%$ confidence level (Tables A2 and B2). The low significance could be attributed to the unsuitability of the model for predicting the variation of ultimate tensile strength with printing speed and extrusion temperature, or to the high experimental standard deviations compared to the variation of the response between each configuration. On the contrary, models with Young's modulus responses are significant at more than the $90 \%$ confidence level. A single optimum was expected from among the disparate results in the literature, but several optima were observed instead (Figure 3a and 3b). The first mathematical model shows an optimum, which is a minimum (Figure 3a). To compensate for the loss of mechanical properties with FFF compared to formative processes, a maximum was desired. The model considers a significant positive first-order coefficient for printing speed, $a_{1}$, while that for extrusion temperature, $a_{2}$, is not significant (Table A1). This maximum can be expected at higher speeds. The second design was constructed by sliding the first design in an iso-thermal fashion $\left(a_{2}=0\right)$ to higher speeds $\left(a_{1}>0\right)$. Three new points were added, while 
keeping four points of the first design, and matrix calculations were carried out again. The results after this iteration led to the presence of another optimum, which was a maximum.

Table 4. Coefficients and residue from the theoretical model for both Doehlert designs using Young's modulus and ultimate tensile strength as responses.

\begin{tabular}{|c|c|c|c|c|c|}
\hline & \multirow{2}{*}{ Coefficient } & \multicolumn{2}{|c|}{ First design } & \multicolumn{2}{|c|}{ Second design } \\
\hline & & $E$ & $\sigma_{M}$ & $E$ & $\sigma_{M}$ \\
\hline Constant & $a_{0}$ & 1249.0 & 59.00 & 1397.0 & 59.40 \\
\hline Printing speed & $\mathrm{a}_{1}$ & 33.1 & 1.78 & 38.0 & -0.25 \\
\hline Temperature & $\mathrm{a}_{2}$ & -6.6 & -1.88 & 1.2 & -1.36 \\
\hline Printing speed $x$ temperature & $\mathrm{a}_{12}$ & -5.2 & 0.75 & 20.8 & 0.29 \\
\hline $\begin{array}{l}\text { Printing speed } x \text { printing } \\
\text { speed }\end{array}$ & $\mathrm{a}_{11}$ & 122.0 & -0.95 & -91.5 & -0.65 \\
\hline Temperature $\mathrm{x}$ temperature & $a_{22}$ & 57.0 & -3.32 & -36.8 & -2.35 \\
\hline Residue & $\varepsilon$ & 7.2 & 0.43 & 18.5 & 0.01 \\
\hline
\end{tabular}

(a)

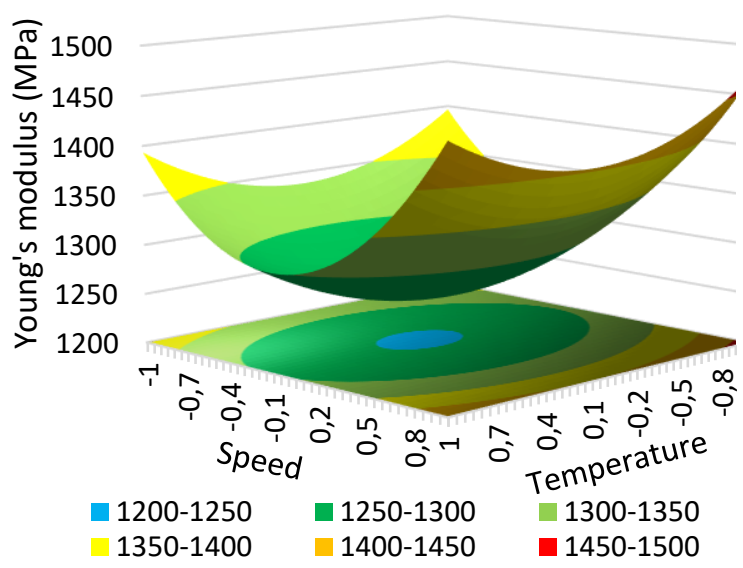

(b)

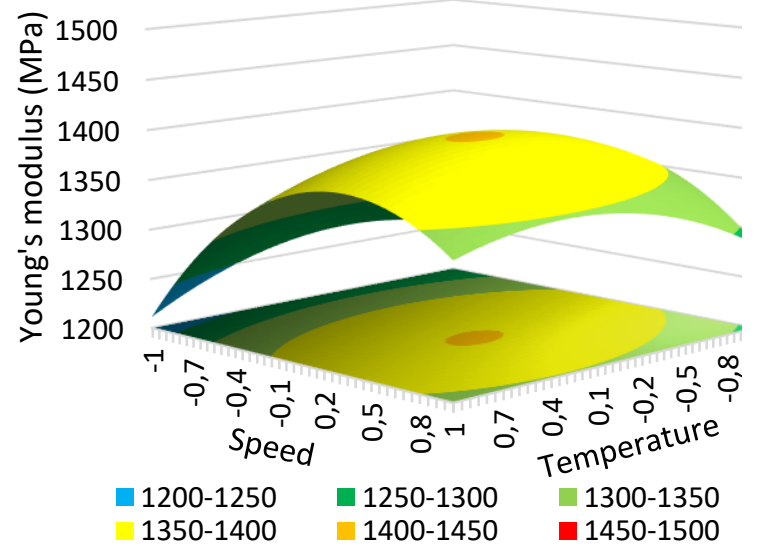


(c)

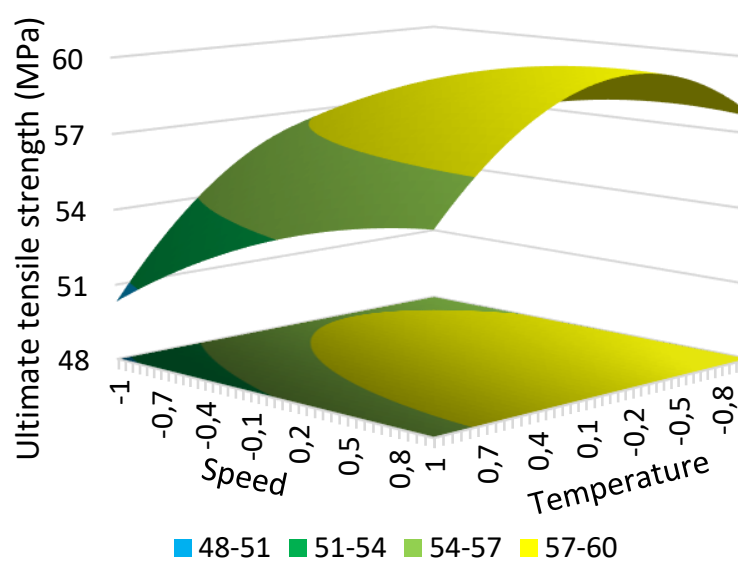

(d)

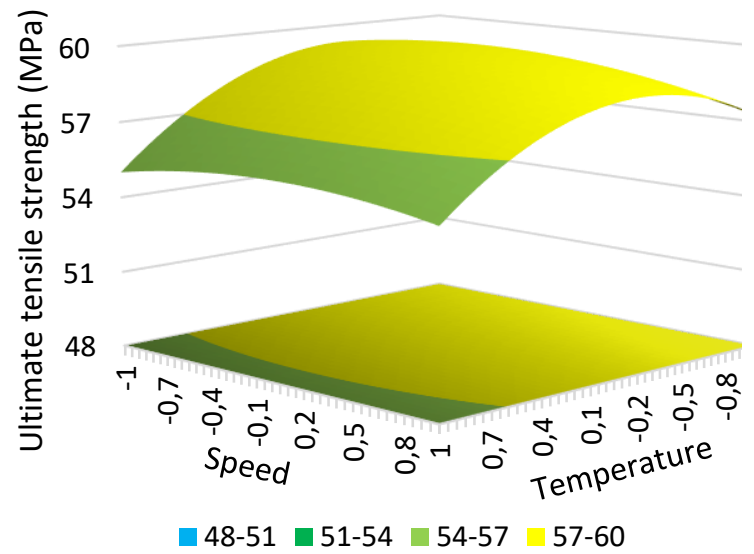

Figure 3. Response surface for Young's modulus (a, b) and ultimate tensile strength (c, d) as responses for the first (a, c) and second Doehlert theoretical models (b, d) as a function of printing speed and temperature in coded units with isoresponse surface projection.

Regarding the coefficient significance for $p$-values lower than $10 \%$, the effects of printing speed and extrusion temperature on Young's modulus follow a second-order polynomial for each design (Tables A1 and B1). Young's modulus is a function of printing speed with first- and second-order terms, $a_{1}$ and $a_{11}$. The dependence with temperature follows only a second-order term, $a_{22}$, while the interaction, $a_{12}$, is null. The difference between the two designs is reflected in the signs of the second-order terms, $a_{11}$ and $a_{22}$ : they are both positive in the first model and negative in the second model. Those values mean that Young's modulus tends to increase globally with printing speed, but not with temperature or printing speed/extrusion temperature interaction. However, the effect of printing speed is locally more nuanced as several local optima are noticed on each design. The change of sign for both second-order terms, $a_{11}$ and $a_{22}$, between the two designs is the reason why a minimum is observed on one design and a maximum is observed on the other one. Although the interaction term is null for both models, the effect of extrusion temperature is dependent on the range of printing speed. Those observations point out a more complex model for predicting Young's modulus plotted against printing speed and extrusion temperature. Indeed, Young's modulus seems to follow globally a third-order polynomial model, which could lead to disparate local effects. As an example, Montero et al. ${ }^{36}$ reported that extrusion temperature did not affect tensile strength, whereas Spoerk et al. ${ }^{20}$ and Alafaghani and Qattawi ${ }^{37}$ stated that extrusion temperature had a remarkable positive effect. Because of the interaction with a large range of printing speed, the effect may be different from one study to another. Similarly, the use of only two values per factor could cause a gap between the actual and observed effects; the presence of an optimum could be hidden and only the effect of the first-order term may be visible. 
Figures $2 \mathrm{a}$ and $2 \mathrm{~b}$ show that printing speed has a negative effect on Young's modulus, followed by positive and negative effects. These different effects of printing speed are in agreement with the literature ${ }^{14-17}$ and are likely dependent on the study conditions. The complexity of the printing speed effect on Young's modulus could be attributed to numerous physical phenomena, such as adhesion, distortion, crystallinity, and so on.

\subsection{Physical explanation}

In the first Doehlert design, the second-order term of the printing speed, $a_{11}$, had the greatest effect on tensile properties and led to a highly curved surface. Competition between inner residual stresses and bond formation may be important. Zhang and $\mathrm{Chou}^{38}$ concluded that increasing print speed led to a greater thermal cycle frequency and higher residual stresses, which worsen mechanical properties. The residual stresses may be due to distortion caused by a gradient of crystallinity ${ }^{12,39}$. DSC measurements of the two first printed layers and the two last layers show different crystallinity rates (Figure 4). The bottom of the tensile test specimen shows a cold crystallisation enthalpy of the same order as the melting enthalpy, while the top shows a similar melting enthalpy, but a lower cold crystallisation enthalpy. As a result, the crystallinity rate is calculated to be around $1.4 \pm 1.1 \%$ for the first printed layers and around $38.1 \pm 3.3 \%$ for the last layers, which is due to the lower temperature of the build plate compared to the temperature of the deposited layers. The difference of temperature of the subtract leads to a differential of cooling rate, slower for the latest layers, that causes higher crystallinity rate with the height position. A gradient of crystallinity is observed, and this can cause distortion and lower mechanical properties as a function of the printing speed ${ }^{12}$, although composite materials are less subject to distortion than neat materials as shrinkage is less pronounced when materials are filled.

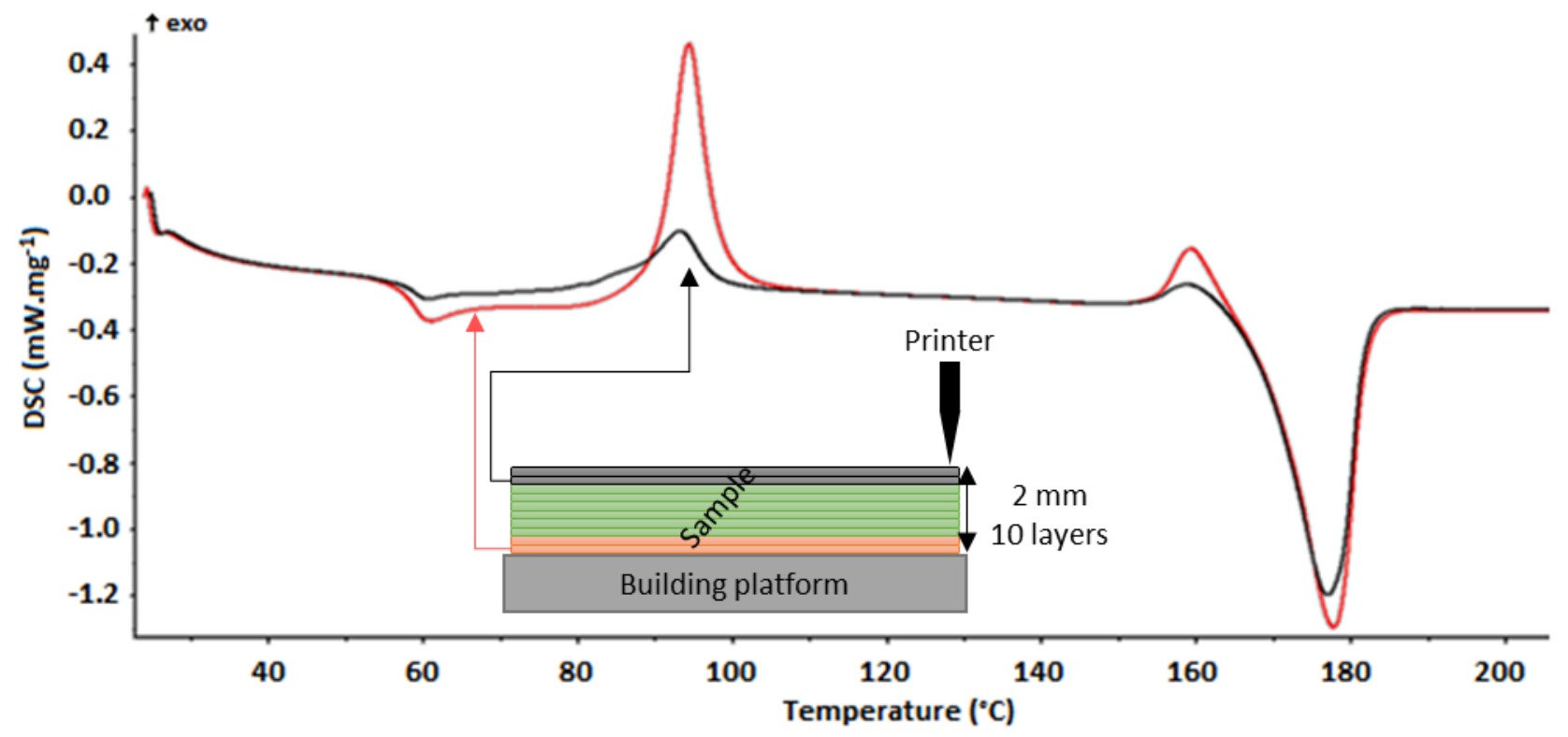

Figure 4. Comparison of DSC thermograms for the two first layers (red) and the two last layers (black) of tensile specimens printed at $215^{\circ} \mathrm{C}$ and $75 \mathrm{~mm} \cdot \mathrm{s}^{-1}$ (test $\mathrm{N}^{\circ} 1$ ). 
On the one hand, a faster printing speed was associated with a higher shear rate. The shear rate was calculated as

$$
\dot{\gamma}=\frac{4 Q}{\pi R^{3}} \frac{3 n+1}{4 n}
$$

$Q$ is the flow rate, which is approximately the product of the printing speed, the layer height and the raster width, $R$ is the radius of the outlet nozzle, and $n$ is the flow behaviour index obtained from rheological measurements (Figure 5).

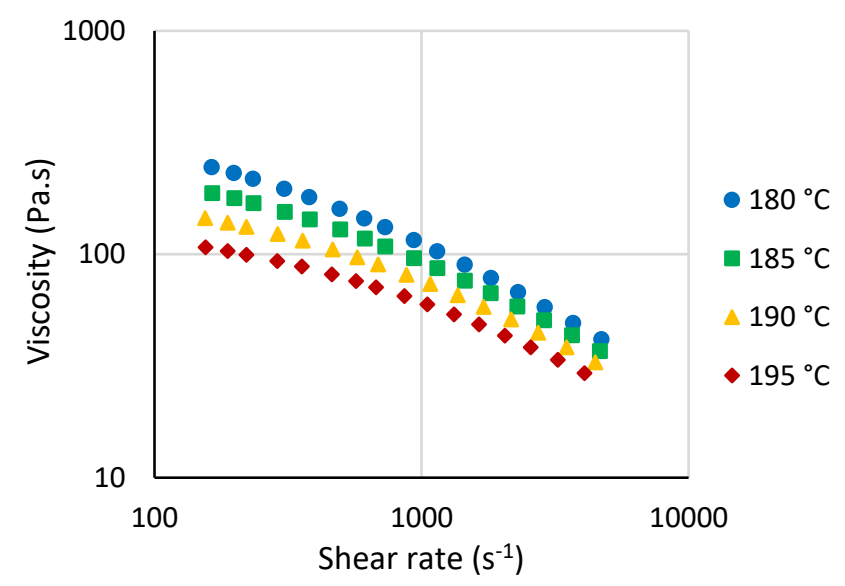

Figure 5. Viscosity of a PLA/layered silicate nanocomposite plotted against shear rate at different temperatures as determined by capillary rheology after Bagley and Rabinovitsch corrections.

The shear rate in the Doehlert designs was estimated to be between $250 \mathrm{~s}^{-1}$ and $5000 \mathrm{~s}^{-1}$, which is in the range of measurements obtained by capillary rheology (Figure 5). Thus, an increase in printing speed reduced the viscosity, which would facilitate deposition of the polymer by allowing it to flow more suitably through the nozzle onto the previous layer, similarly to extrusion temperature ${ }^{20}$. Figure 6 illustrates this statement, with each axis view represented by a pair of different configurations. When observed on-edge, especially in the $\mathrm{x}$ - and $\mathrm{y}$-axes views where deposition is visible, when printing speed was low (configuration $\mathrm{N}^{\circ} 4$ ), deposition defects were apparent. Those defects were due to the polymer not being fluid enough under a low shear rate (Figure 5). Because of those defects, Young's modulus and the ultimate tensile strength tend to decrease at lower printing speed, while the mechanical properties increase with a decrease in residual stresses at a lower printing speed, leading to curvature in the response surface. However, the variation of viscosity with the shear rate did not impact bond formation after deposition, when the shear rate was null. On the other hand, the time between adjacent filament depositions is reduced by greatly increasing the printing speed (up to seven times greater from test $\mathrm{N}^{\circ} 4$ to test $\mathrm{N}^{\circ}$ 9), which provides less time for the polymer to cool down. These higher temperatures led to lower viscosity, as seen in Figure 5 and in the literature ${ }^{30,40}$. This phenomenon is more relevant for small specimens like 5A-type specimens in which the deposition time between two adjacent filaments is between 0.1 and 5 seconds - in this Doehlert network - while the time required to reach the glass transition is around 1 to 3 seconds ${ }^{41}$. Depending on the configuration, a filament could be deposited next to the previous deposition either in a "viscous" or 
"glassy" state, which, respectively, facilitates or restricts the interdiffusion of polymer chains between the deposited filaments ${ }^{13}$. A more developed adhesion could be expected with configuration $\mathrm{N}^{\circ} 1$ rather than configuration $\mathrm{N}^{\circ} 4$, as seen on tomographic images. In this way, increasing printing speed increases the shear rate and reduces the time between two filament depositions and then the loss of heat of the adjacent filaments, which tends to give a more fluid material during and right after deposition and favours bond formation between the deposited filament and the previous and adjacent one.

These observations were inconsistent with those from literature ${ }^{15,18,19}$, who reported that high printing speed is a source of deposition defects and that low printing speed enhances the adhesion between deposited filaments. This difference at low printing speed may come from the ability of the materials to suitably flow over the previous deposited layer, which is dependent on the rheological behaviour of the used materials. A critical viscoelastic behaviour may result from one case to another and defects may or may not appear at lower printing speed with other materials. Differences may particularly be noticed between filled or unfilled polymer as filled polymers tend to have greater viscosity at low shear rate than unfilled polymers. This greater viscosity for filled polymers could overpass the critical viscosity from which materials are not fluid enough to be effectively deposited and/or could prevent the adhesion at zero-shear rate by inhibiting polymer chain interpenetration between adjacent filaments because of the hindering filler ${ }^{40}$. Therefore, defects might result from two different mechanisms with a change in printing speed:

(1) a polymer that is not fluid enough at low shear rate decreases the ability of the filament to be effectively deposited over the whole raster width, especially if materials are filled

(2) deposition that is too fast may lead to turbulent flow and inconsistent deposition.

The interaction between printing speed and extrusion temperature could greatly contribute to this difference in observations. Tsouknidas et al. ${ }^{16}$ also observed a monotonous and negative effect of printing speed (from 30 to 220 $\mathrm{mm} \cdot \mathrm{s}^{-1}$ ) on the maximum stress. In contrast, the Doehlert designs revealed an initial negative effect, then positive and negative effects from 15 to $105 \mathrm{~mm} \cdot \mathrm{s}^{-1}$. This difference could be due to thermo-kinetic interaction and the use of other printing conditions, since Tsouknidas et al. ${ }^{16}$ used a constant temperature of $180{ }^{\circ} \mathrm{C}$ for PLA, with an infill percentage of $50 \%$. Due to this low temperature and partial filling, which accentuates heat loss due to convection and reduces the heat transfer between filaments through conduction ${ }^{42}$, interpenetration of the polymer chains would be limited. Thus, only a phenomenon that gives deposition defects would be involved and would only reduce the mechanical properties as a function of printing speed. The curvature on the surface responses is the expression of several phenomena acting on the deposition of the filaments. 


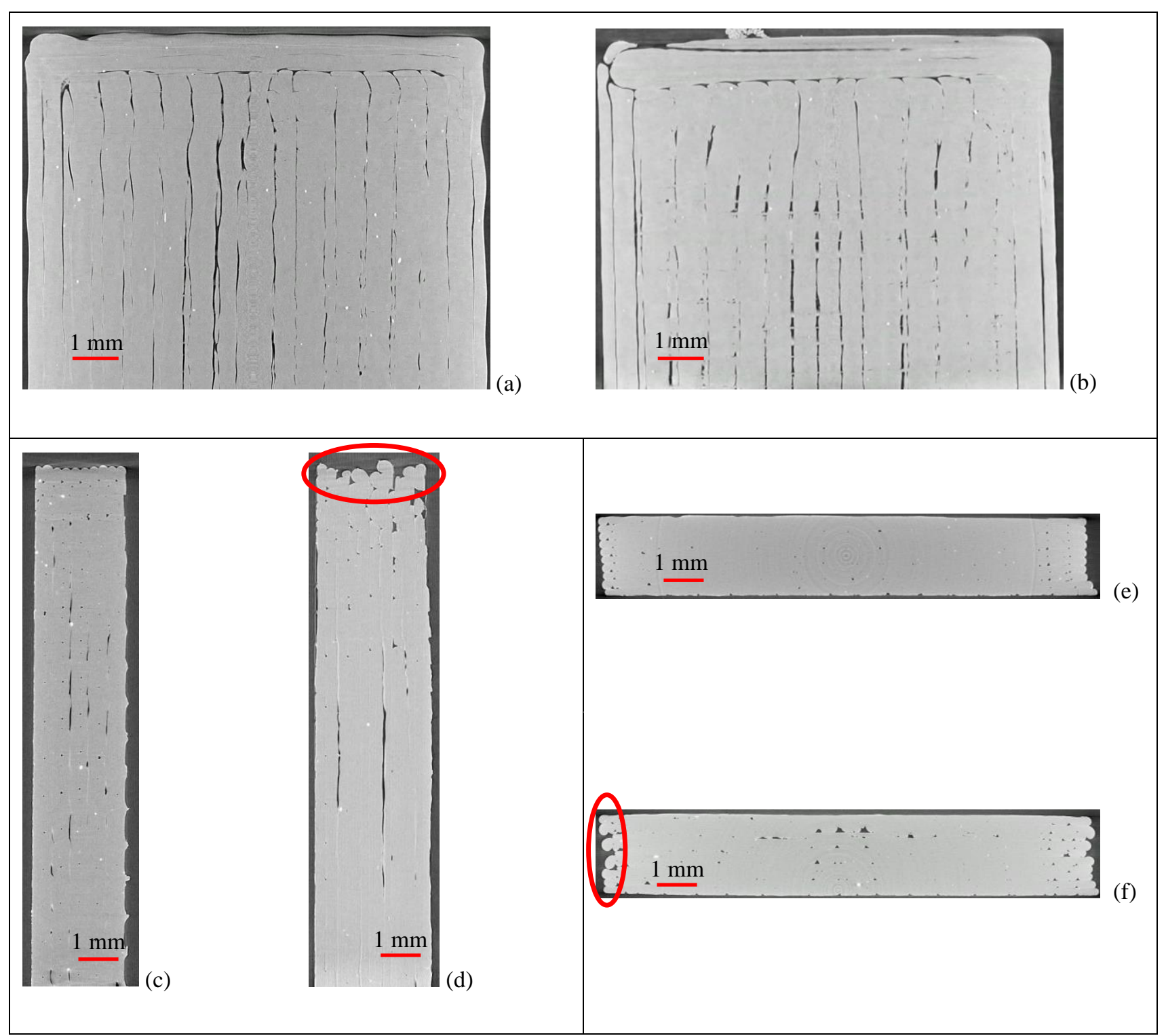

Figure 6. Images from microCT of printed sample (grip zone) with a cross-sectional view in the $\mathrm{z}$-axis (a, b), $\mathrm{x}$-axis (c,

d), and y-axis (e, f) at configuration $\mathrm{N}^{\circ} 1\left(\mathrm{a}, \mathrm{c}, \mathrm{e}: 75 \mathrm{~mm} \cdot \mathrm{s}^{-1}\right.$ at $\left.215^{\circ} \mathrm{C}\right)$ and configuration $\mathrm{N}^{\circ} 4\left(\mathrm{~b}, \mathrm{~d}, \mathrm{f}: 15 \mathrm{~mm} \cdot \mathrm{s}^{-1}\right.$ at 215

$\left.{ }^{\circ} \mathrm{C}\right)$. Circles enlighten the observed defects.

The capacity of the filament to be effectively deposited would directly impact the mesostructure and therefore the mechanical properties. This new competition between the ability to be deposited on the whole raster width and the ability to be deposited consistently leads to a new optimum of mechanical properties at higher speeds. Indeed, increasing printing speed would lower the viscosity and facilitate deposition of the material, until the deposition is too fast and causes new defects due to turbulent flow that decreases the adhesion between layers. The optimum would then be a maximum, as observed with the second Doehlert design. Figure 7 illustrates this phenomenon by comparing the fracture zone of the printed tensile test specimens at the same extrusion temperature but different printing speeds. 
Printing at the lowest speed, $15 \mathrm{~mm} . \mathrm{s}^{-1}$, leads to triangular voids (Figure 7a). Those voids are representative of depositions that do not occur over the whole raster width. The filament is in contact with the previous layer but is not fluid enough to be deposited over the entire raster width. In addition, on the edges of the tensile specimen, the deposition fills gaps with very low precision. At a higher speed, $45 \mathrm{~mm} \cdot \mathrm{s}^{-1}$ (Figure 7b), defects are still visible but less pronounced. Among other features, the contours are better defined, and the overall porosity seems lower. At an even faster speed (Figure 7c), deposition is ideal, with little porosity. The deposition is regular, and the printing accuracy is greatly improved compared to the two previous speeds. This configuration is test $\mathrm{N}^{\circ} 1,75 \mathrm{~mm} \cdot \mathrm{s}^{-1}$ and $215^{\circ} \mathrm{C}$, which experimentally gave the highest values. The highest speed, $105 \mathrm{~mm} \cdot \mathrm{s}^{-1}$ (Figure $7 \mathrm{~d}$ ), led to the creation of new defects. The pores outside the contours are not triangular, but rather are elongated, which is attributed to the lack of adhesion of the filament under rapid deposition. This phenomenon does not allow effective contact between the inter-layer filaments. At high speed, the filament would not interfere with the previous layer over a portion of the raster length. In this way, the porosity increases again, and this explains the inferior mechanical properties of the configuration at $105 \mathrm{~mm} . \mathrm{s}^{-1} \mathrm{compared}$ to the configuration at $75 \mathrm{~mm} \cdot \mathrm{s}^{-1}$. The two deposition defect modes act on different steps of adhesion ${ }^{13}$. Sun et al $^{24}$ essentially focused on diffusion at the interface in terms of temperature, but modification of printing speed would also act on the bonding quality between filaments via surface contact and the initial neck growth. On one hand, at low print speed, the deposition is in contact, but only partially, with the raster width, which decreases the ability of the deposition to fully develop contact between filaments by reducing the initial neck growth. On the other hand, at high speed, the deposition is inconsistent, with no contact on some portions of the raster, which prevents the adhesion process.

(a)

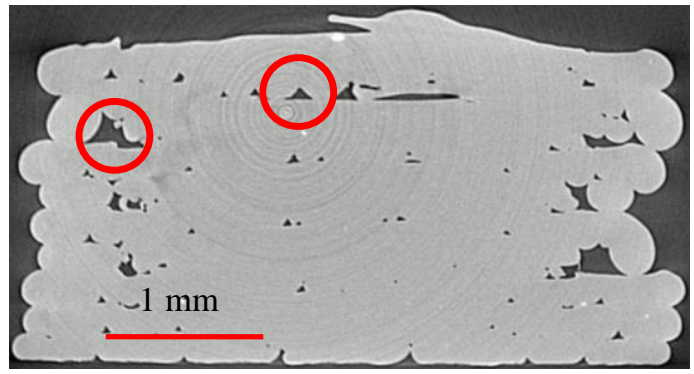

(c)

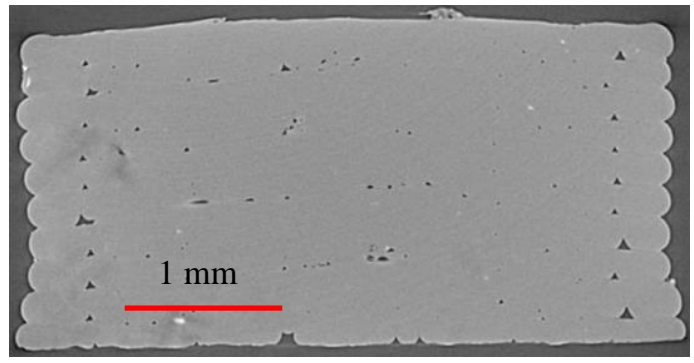

(b)

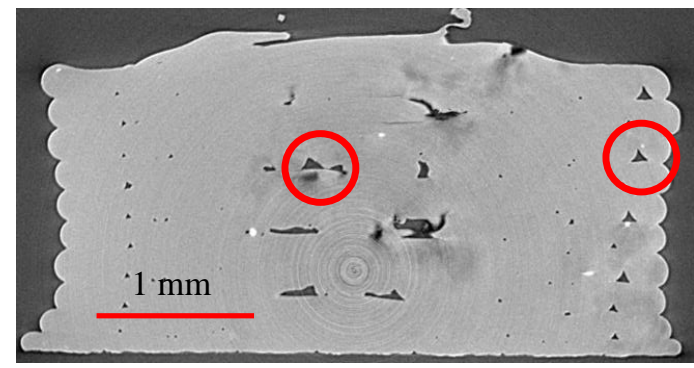

(d)

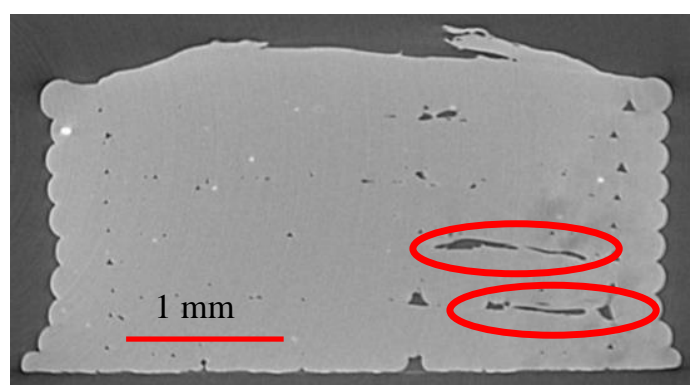


Figure 7. Images from microCT of fracture zones with a cross-sectional view on the $y$-axis of tensile specimens printed at $215^{\circ} \mathrm{C}$ and (a) $15 \mathrm{~mm} \cdot \mathrm{s}^{-1}$ (test $\mathrm{N}^{\circ}$ 4), (b) $45 \mathrm{~mm} \cdot \mathrm{s}^{-1}$ (test $\mathrm{N}^{\circ} 7$ ), (c) $75 \mathrm{~mm} \cdot \mathrm{s}^{-1}$ (test $\mathrm{N}^{\circ} 1$ ), and (d) $105 \mathrm{~mm} \cdot \mathrm{s}^{-1}$ (test $\mathrm{N}^{\circ}$ 9). Circles enlighten the observed defects.

The ability of the filament to be effectively deposited would directly modify the porosity of the product. To verify the impact of porosity on mechanical properties, the filling rate was measured. All configurations were tested, and the filling rate was used with the two Doehlert designs. Young's modulus and the ultimate tensile strength are weakly correlated to the filling rate with coefficients of determination equal to 0.3312 and 0.0791 , respectively, via linear regression. By applying the RSM with the filling rate in response, it appears that the surfaces show a minimax for the first design and a maximum for the second design at a more than $90 \%$ confidence level (Figure 8 ). The presence of a maximum could indicate that porosity significantly impacts the mechanical properties, but its effect is counteracted by other phenomena that reduce the correlation between porosity and mechanical properties. Those phenomena can contribute as much to the creation of internal residual stresses as the development of adhesion between deposited filaments. This last phenomenon not only considers the contact surface, depending on the porosity, but also the interpenetration of the polymer chains between the deposited filaments, which is not visible in microCT images. The minimum mechanical properties could be due to competition between internal stresses and fluidification of the material, which are properties at the molecular scale and at the scale of the mesostructure. Therefore, the filling rate may not necessarily pass through a minimum. The porosity could play a role in the optimisation of mechanical properties, but its effect is not dominant over the effects of other phenomena.

(a)

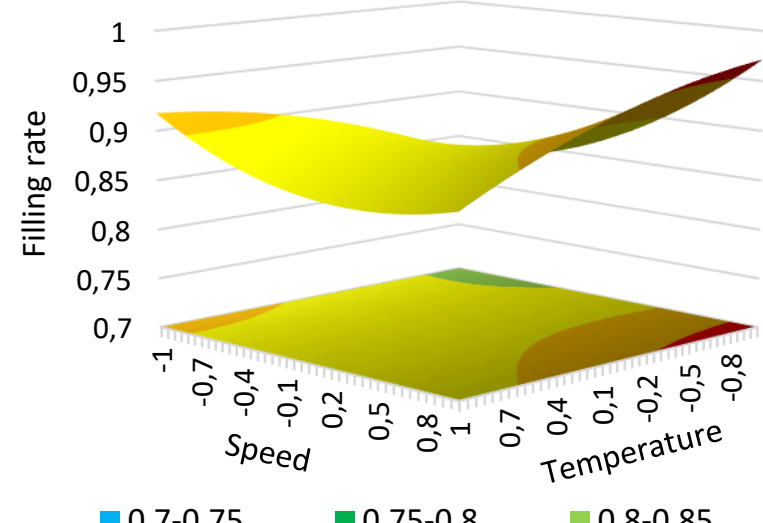

(b)

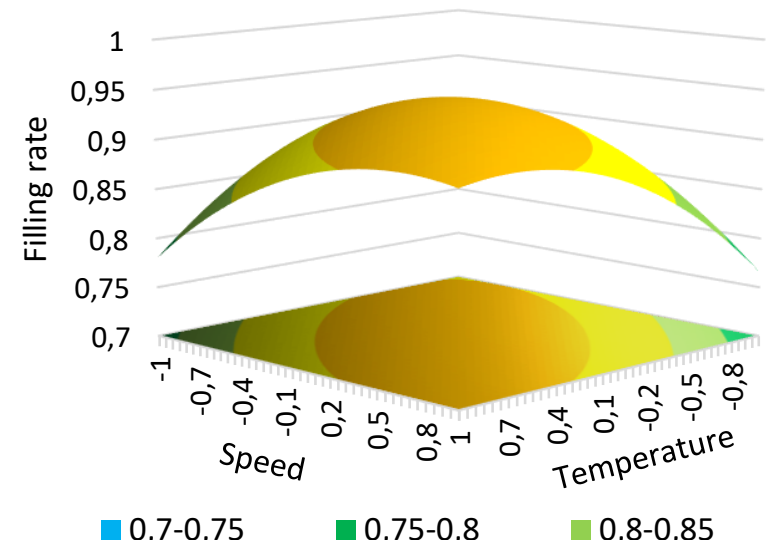

Figure 8. Response surface for (a) the first Doehlert design and (b) the second design with the filling rate as a response as a function of printing speed and the temperature in coded units. 
The crystallinity rate was measured for all configurations to assess its effect on tensile properties compared to the effect of the filling rate. Wittbrodt and Pearce ${ }^{43}$ previously observed a lack of correlation between the crystallinity rate and yield stress with changes in extrusion temperature, but the correlation could differ with printing speed. Three points in the fracture zone of one tensile test specimen per configuration were measured by DSC analyses. The crystallinity rate varied from 11.4 to $14.3 \%$, but the standard deviations did not exceed $0.2 \%$. As observed in Figure 4, a crystallinity rate gradient was revealed between the bottom and the top of the same tensile test specimen. Low standard deviations with three different points in the fracture zone may reveal a constant longitudinal gradient. Models were then significant at a more than $90 \%$ confidence level.

The coefficient of determination for a linear regression with the two mechanical properties as a function of the crystallinity rate was 0.2275 and 0.0269 , respectively, indicating a very weak correlation between the mechanical properties and the crystallinity rate. As with the filling rate, the degree of crystallinity was used as a response. The response surfaces have a minimax and then a minimum response from the first to the second design (Figure 9). The same trend was not observed between the mechanical properties and the crystallinity rate as a function of printing speed and extrusion temperature. The printing parameters influence the crystallinity rate, but do not appear to have a major impact on the mechanical properties.

Wittbrodt and Pearce ${ }^{43}$ reported that temperature has a relatively linear positive effect on mechanical properties. In fact, this effect appears to be a second-order one. In rheology, an increase in temperature decreases the viscosity and a higher temperature would tend to increase the mechanical properties by developing the adhesion between the filaments ${ }^{20,24}$, due to faster interpenetration kinetics. The contribution of temperature in thermal cycles and thus internal residual stresses ${ }^{38}$ and/or thermal degradation due to intra- and inter-molecular exchange, cis-elimination and concerted radical and nonradical reactions above $200{ }^{\circ} \mathrm{C}^{44}$ could have a significant effect and explain the decrease in properties at $215^{\circ} \mathrm{C}$ and above in the second Doehlert design. One should note that the addition of clay may contribute to the thermal degradation of the polymer matrix by hydrolysis ${ }^{45}$ because of the capacity of this filler to adsorb moisture ${ }^{40,46}$. This phenomenon could be more pronounced for filled materials than unfilled ones if attention is not paid on the drying process before printing. Although temperature has less of an effect than printing speed, the inverse trend of the temperature effect is not explained and could be due to multiple phenomena. Creation of internal residual stresses, ability of materials to be effectively deposited and to weld, modification of the mesostructure, matrix degradation, and crystallisation are all phenomena that can modify the mechanical properties without any being dominant over another. They might express themselves differently according to printing speed and extrusion temperature. 
(a)

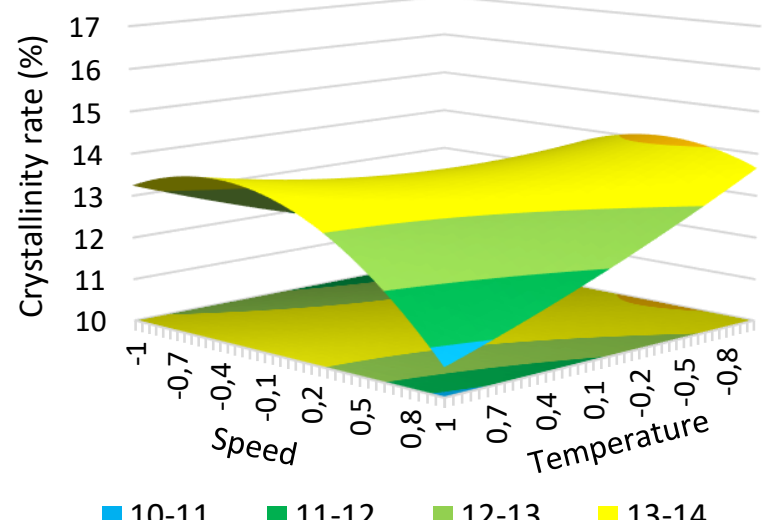

(b)

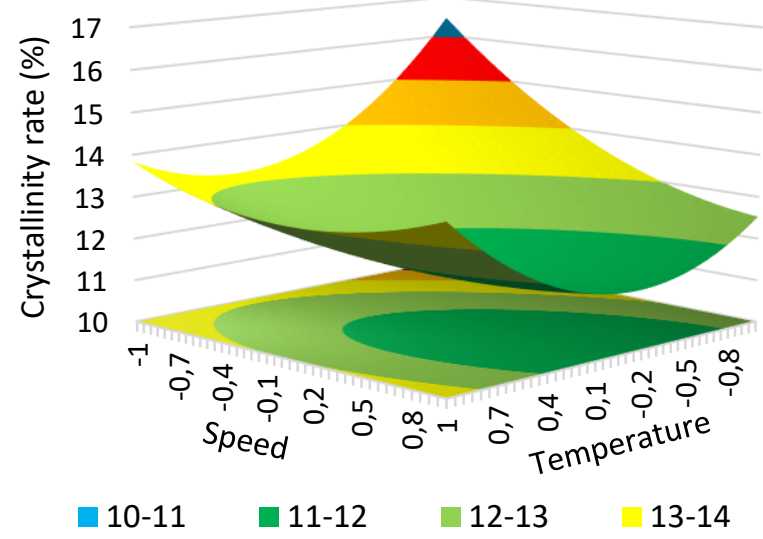

Figure 9. Response surface for (a) the first Doehlert design and (b) the second design with the crystallinity rate as a response as a function of printing speed and the temperature in coded units.

\section{Conclusions and perspectives}

Doehlert designs coupled with calorimetry, rheology and tomography were used to better understand the impact of FFF process parameters on tensile properties. The results imply that interpenetration of polymer chains between deposited filaments is not the only major phenomenon that impacts the mechanical properties in terms of thermo-kinetic parameters, especially with composites as interpenetration is reduced by the presence of a filler. Changes in those parameters can both increase and decrease the mechanical properties because of bond formation, abundance of residual stress, crystallisation process, and deposition ability. Because of this complexity of thermo-kinetic interaction, the manufacturing of printed parts should be optimised without dissociation of the temperature and printing speed. The results also showed that rheology under flow modifies the way the filament is deposited, before interpenetration at a zero-shear rate, which in turn impacts the mesostructure. The mechanical properties are then strongly dependent on both linear and non-linear rheology, which implies a certain knowledge of the printed materials behaviour, particularly for composites and the effect on rheology of their filler under flow as viscosity is increased at low shear rate but decreased at high shear rate. Filled materials appeared more suitable for printing at moderate and high printing speed, around 75 $\mathrm{mm} . \mathrm{s}^{-1}$, compared to unfilled materials that are more suitable for low printing speed. Mesostructure optimisation through this DOE might be of interest for architectural control in bone tissue engineering for example.

RSM is recommended for the optimisation of mechanical properties because of the complexity and number of phenomena. The iterative nature of Doehlert designs appeared to be suitable for observing multiple optima for optimisation. This study revealed the efficiency of such method with additive manufacturing, which is recommended for 
complex system whose the evolution of properties with manufacturing parameters does not correspond to a second-order model like central composite or Box-Behnken designs. Different models are then observed on an entire domain with the use of the Doehlert method, which increases the resolution of the factor effects and broadens the understanding of the results and their physical explanations.

\section{Acknowledgements}

The project PolyFabAdd is co-funded by the European Union. Europe invests in Champagne-Ardenne with the European Regional Development Fund. The authors gratefully acknowledge the Région Champagne-Ardenne (France) [grant number D201501201] and the European Union for their financial support [grant number D201505025]. This project is also included in the MATUR Chair, co-financed by the Région Champagne-Ardenne (France) [grant number D201507798], the European Union [grant number D201507799] and UIMM [Partners convention $\mathrm{n}^{\circ}$ 13-2015]. We would also like to thank Mr Philippe Dony and Mr Stéphane Buet for their technical support in this project, and Mrs Annie Leclerc for the proofreading.

\section{Appendix}

A. ANOVA - First Doehlert design

Table A1. Analysis of variance of the coefficients from the first Doehlert models using Young's modulus and ultimate tensile strength as responses.

\begin{tabular}{ccllll}
\hline Response & Coefficient & Value & $\begin{array}{l}\text { Standard } \\
\text { deviation }\end{array}$ & $\boldsymbol{t}$-value & $\boldsymbol{p}$-value \\
\hline$a_{0}$ & 1249 & 4.3289 & 288.526 & $\mathbf{0 . 0 0 2 2}$ \\
$a_{1}$ & 33.1333 & 4.3289 & 7.6540 & $\mathbf{0 . 0 8 2 7}$ \\
& $a_{2}$ & -6.6395 & 4.3289 & -1.5338 & 0.3678 \\
& $a_{12}$ & -5.1962 & 4.3289 & -1.2003 & 0.4422 \\
& $a_{11}$ & 121.9500 & 4.3289 & 28.1712 & $\mathbf{0 . 0 2 2 6}$ \\
& $a_{22}$ & 57.0167 & 4.3289 & 13.1712 & $\mathbf{0 . 0 4 8 2}$ \\
\hline$a_{0}$ & 59 & 0.2907 & 202.967 & $\mathbf{0 . 0 0 3 1}$ \\
& $a_{1}$ & 1.7833 & 0.2907 & 6.1349 & 0.1029 \\
& $a_{2}$ & -1.8764 & 0.2907 & -6.4550 & $\mathbf{0 . 0 9 7 8}$ \\
& $a_{12}$ & 0.7506 & 0.2907 & 2.5820 & 0.2352 \\
& $a_{11}$ & -0.9500 & 0.2907 & -3.2681 & 0.1890 \\
& $a_{22}$ & -3.3167 & 0.2907 & -11.4097 & $\mathbf{0 . 0 5 5 7}$
\end{tabular}

Table A2. Analysis of variance of the theoretical models from the first Doehlert design using Young's modulus and ultimate tensile strength as responses.

\begin{tabular}{cllllll}
\hline \multirow{2}{*}{ Response } & $\begin{array}{l}\text { Source of } \\
\text { variation }\end{array}$ & $\begin{array}{l}\text { Sum of } \\
\text { squares }\end{array}$ & ddl & Mean square & F-value & $\boldsymbol{p}$-value \\
\hline \multirow{2}{*}{$\boldsymbol{E}$} & Model & 13471.5783 & 5 & 2694.3157 & 4.1080 & $\mathbf{0 . 0 0 6 1}$
\end{tabular}




\begin{tabular}{lllllll} 
& Total & 32491.9867 & 34 & & & \\
\hline \multirow{3}{*}{$\boldsymbol{\sigma}_{\boldsymbol{M}}$} & Model & 28.6276 & 5 & 5.7255 & 1.9360 & 0.1188 \\
& Error & 85.7667 & 29 & 2.9575 & & \\
& Total & 114.3943 & 34 & & & \\
\hline
\end{tabular}

B. ANOVA - Second Doehlert design

Table B1. Analysis of variance of the coefficients from the second Doehlert models using Young's modulus and ultimate tensile strength as responses.

\begin{tabular}{|c|c|c|c|c|c|}
\hline Response & Coefficient & Value & $\begin{array}{l}\text { Standard } \\
\text { deviation }\end{array}$ & t-value & $p$-value \\
\hline \multirow{6}{*}{$\boldsymbol{E}$} & $a_{0}$ & 1397 & 4.3191 & 323.446 & 0.0020 \\
\hline & $a_{1}$ & 38.0000 & 4.3191 & 8.7981 & 0.0720 \\
\hline & $a_{2}$ & 1.1547 & 4.3191 & 0.2673 & 0.8337 \\
\hline & $a_{12}$ & 20.7846 & 4.3191 & 4.8122 & 0.1304 \\
\hline & $a_{11}$ & -91.5000 & 4.3191 & -21.1849 & 0.0300 \\
\hline & $a_{22}$ & -36.8333 & 4.3191 & -8.5298 & 0.0743 \\
\hline \multirow{6}{*}{$\sigma_{M}$} & $a_{0}$ & 59.4 & 0.2619 & 226.772 & 0.0028 \\
\hline & $a_{1}$ & -0.2500 & 0.2619 & -0.9544 & 0.5148 \\
\hline & $a_{2}$ & -1.3568 & 0.2619 & -5.1798 & 0.1214 \\
\hline & $a_{12}$ & 0.2887 & 0.2619 & 1.1021 & 0.4691 \\
\hline & $a_{11}$ & -0.6500 & 0.2619 & -2.4815 & 0.2439 \\
\hline & $a_{22}$ & -2.3500 & 0.2619 & -8.9716 & 0.0707 \\
\hline
\end{tabular}

Table B2. Analysis of variance of the theoretical models from the second Doehlert design using Young's modulus and ultimate tensile strength as responses.

\begin{tabular}{clllllc}
\hline \multirow{2}{*}{ Response } & $\begin{array}{l}\text { Source of } \\
\text { variation }\end{array}$ & $\begin{array}{l}\text { Sum of } \\
\text { squares }\end{array}$ & ddl & Mean square & F-value & $\boldsymbol{p}$-value \\
\hline \multirow{2}{*}{$\boldsymbol{E}$} & Model & 10430.5000 & 5 & 2086.1000 & 3.1951 & $\mathbf{0 . 0 2 0 3}$ \\
& Error & 18934.5900 & 29 & 652.9169 & & \\
& Total & 29365.0900 & 34 & & 0.8219 & 0.5442 \\
\multirow{2}{*}{$\boldsymbol{\sigma}_{\boldsymbol{M}}$} & Model & 3.8686 & 5 & 1.9737 & & \\
& Error & 69.6400 & 29 & 34.4014 & & \\
\hline
\end{tabular}

\section{References}

1. Guo, N.; Leu, M. C. Front. Mech. Eng. 2013, 8, 215.

2. Wang, X.; Jiang, M.; Zhou, Z.; Gou, J.; Hui, D. Compos. Part B Eng. 2017, 110, 442.

3. de Leon, A. C.; Chen, Q.; Palaganas, N. B.; Palaganas, J. O.; Manapat, J.; Advincula, R. C. React. Funct. Polym. 2016, $103,141$.

4. $\quad$ Dawoud, M.; Taha, I.; Ebeid, S. J. J. Manuf. Process. 2016, 21, 39.

5. Ngo, T. D.; Kashani, A.; Imbalzano, G.; Nguyen, K. T. Q.; Hui, D. Compos. Part B Eng. 2018, $143,172$.

6. Nouri, H.; Guessasma, S.; Belhabib, S. J. Mater. Process. Technol. 2016, 234, 113.

7. Mukherjee, T.; Manvatkar, V.; De, A.; DebRoy, T. Scr. Mater. 2017, 127, 79.

8. Ahn, S.; Montero, M.; Odell, D.; Roundy, S.; Wright, P. K. Rapid Prototyp. J. 2002, 8, 248.

9. Popescu, D.; Zapciu, A.; Amza, C.; Baciu, F.; Marinescu, R. Polym. Test. 2018, 69, 157. 
10. El Magri, A.; El Mabrouk, K.; Vaudreuil, S.; Chibane, H.; Touhami, M. E. J. Appl. Polym. Sci. 2020, $137,49087$.

11. Yao, T.; Ye, J.; Deng, Z.; Zhang, K.; Ma, Y.; Ouyang, H. Compos. Part B Eng. 2020, 188, 107894.

12. Spoerk, M.; Holzer, C.; Gonzalez-Gutierrez, J. J. Appl. Polym. Sci. 2020, 137, 48545.

13. Bellehumeur, C.; Li, L.; Sun, Q.; Gu, P. J. Manuf. Process. 2004, 6, 170.

14. Deng, X.; Zeng, Z.; Peng, B.; Yan, S.; Ke, W. Materials 2018, 11, 216.

15. Sukindar, N. A. B.; Jaafar, A. B. ARPN J. Eng. Appl. Sci. 2017, 12, 6.

16. Tsouknidas, A.; Pantazopoulos, M.; Katsoulis, I.; Fasnakis, D.; Maropoulos, S.; Michailidis, N. Mater. Des. 2016, 102, 41.

17. Chacón, J. M.; Caminero, M. A.; García-Plaza, E.; Núñez, P. J. Mater. Des. 2017, 124, 143.

18. Gardner, J. M.; Hunt, K. A.; Ebel, A. B.; Rose, E. S.; Zylich, S. C.; Jensen, B. D.; Wise, K. E.; Siochi, E. J.; Sauti, G. Adv. Mater. Technol. 2019, 4, 1800653.

19. Nabipour, M.; Akhoundi, B.; Bagheri Saed, A. J. Appl. Polym. Sci. 2020, 137, 48717.

20. Spoerk, M.; Arbeiter, F.; Cajner, H.; Sapkota, J.; Holzer, C. J. Appl. Polym. Sci. 2017, 134, 45401.

21. Ding, Q.; Li, X.; Zhang, D.; Zhao, G.; Sun, Z. J. Appl. Polym. Sci. 2020, 137, 48786.

22. El Magri, A.; El Mabrouk, K.; Vaudreuil, S.; Ebn Touhami, M. J. Appl. Polym. Sci. 2020, 49625.

23. Yang, C.; Tian, X.; Li, D.; Cao, Y.; Zhao, F.; Shi, C. J. Mater. Process. Technol. 2017, $248,1$.

24. Sun, Q.; Rizvi, G. M.; Bellehumeur, C. T.; Gu, P. Rapid Prototyp. J. 2008, 14, 72.

25. Mohamed, O. A.; Masood, S. H.; Bhowmik, J. L. Adv. Manuf. 2015, 3, 42.

26. Doehlert, D. H. Appl. Stat. 1970, 19, 231.

27. Araujo, P.; Janagap, S. J. Chromatogr. B 2012, 910, 14.

28. Zaidi, L.; Bruzaud, S.; Bourmaud, A.; MÃ@d ̃̃@ric, P.; Kaci, M.; Grohens, Y. J. Appl. Polym. Sci. 2009, NA.

29. Bekas, D. G.; Hou, Y.; Liu, Y.; Panesar, A. Compos. Part B Eng. 2019, 179, 107540.

30. Gu, S.-Y.; Ren, J.; Wang, Q.-F. J. Appl. Polym. Sci. 2004, 91, 2427.

31. Shofner, M. L.; Lozano, K.; Rodríguez-Macías, F. J.; Barrera, E. V. J. Appl. Polym. Sci. 2003, 89, 3081.

32. Jollands, M.; Gupta, R. K. J. Appl. Polym. Sci. 2010, 118, 1489.

33. Krishnamachari, P.; Zhang, J.; Lou, J.; Yan, J.; Uitenham, L. Int. J. Polym. Anal. Charact. 2009, $14,336$.

34. Li, L.; Sun, Q.; Bellehumeur, C.; Gu, P. J. Manuf. Process. 2002, 4, 129.

35. Di Lorenzo, M. L. J. Appl. Polym. Sci. 2006, 100, 3145.

36. Montero, M.; Roundy, S.; Odell, D.; Ahn, S.-H.; Wright, P. K. Soc. Manuf. Eng. 2001, 10.

37. Alafaghani, A.; Qattawi, A. J. Manuf. Process. 2018, 36, 164.

38. Zhang, Y.; Chou, K. Proc. Inst. Mech. Eng. Part B J. Eng. Manuf. 2008, 222, 959.

39. Armillotta, A.; Bellotti, M.; Cavallaro, M. Robot. Comput.-Integr. Manuf. 2017.

40. Ginoux, G.; Dony, P.; Vroman, I.; Alix, S. Rheol. Acta 2020.

41. Seppala, J. E.; Hoon Han, S.; Hillgartner, K. E.; Davis, C. S.; Migler, K. B. Soft Matter 2017, $13,6761$.

42. Costa, S. F.; Duarte, F. M.; Covas, J. A. J. Mater. Process. Technol. 2017, 245, 167.

43. Wittbrodt, B.; Pearce, J. M. Addit. Manuf. 2015, 8, 110.

44. Castro-Aguirre, E.; Iñiguez-Franco, F.; Samsudin, H.; Fang, X.; Auras, R. Adv. Drug Deliv. Rev. $2016,107,333$.

45. Lim, L.-T.; Auras, R.; Rubino, M. Prog. Polym. Sci. 2008, 33, 820.

46. Saiter, A.; Delpouve, N.; Dargent, E.; Oberhauser, W.; Conzatti, L.; Cicogna, F.; Passaglia, E. Eur. Polym. J. 2016, 78, 274. 